\title{
Motivation for Knowledge Work
}

\author{
Paul H.J. Hendriks \\ Radboud University Nijmegen, The Netherlands \\ Célio A.A. Sousa \\ Radboud University Nijmegen, The Netherlands
}

\section{INTRODUCTION}

The importance of motivation in knowledge work is generally acknowledged. With lacking motivation, the quality of the products of knowledge work is bound to drop dramatically. Without work motivation, individual knowledge workers may direct their efforts to their individual needs at the expense of organization goals or decide to leave the firm. Creativity, knowledge teamwork, knowledge sharing, and other knowledge processes depend on the motivation of knowledge workers. Lacking sustained motivation in association with an insufficiently knowledge-friendly culture has often been mentioned as the principal culprit for failed knowledge management (KM) initiatives and programs (Davenport, DeLong, \& Beers, 1998; McKenzie, Truc, \& Winkelen, 2001). Several traits of knowledge workers explain, so it is argued, why prevailing work motivation programs will not work when applied to knowledge workers: they have high needs for autonomy, their career formation is external to the organization, they are loyal to their networks of peers and to their profession rather than to the organization that employs them, and the exact form and sequence of their work processes cannot be fully predicted (Despres \& Hiltrop, 1996).

\section{BACKGROUND}

Motivation is a big issue in KM debates. Notwithstanding its recognized relevance to KM, knowledge about motivation issues in the KM arena is scarce and scattered. Huber (2001, p. 72) argues that "the management practice literature is replete with reports of practices being used to motivate a firm's knowledge workers... to participate with commitment in the firms' knowledge management system." Empirical research on the effectiveness of such practices, however, is in short supply. With respect to the connection between KM practice and motivation for knowledge work, our ignorance exceeds our knowledge
(Huber, 2001). Whereas empirical research on the impact of KM practices on motivation is lacking, research does exist that addresses how motivation affects aspects of knowledge work. This research can be divided into two classes. Firstly, several studies link motivation issues to the broad categories of knowledge work and knowledge workers. Questions addressed in these studies are how motivation explains knowledge worker turnover or which role career development plays in knowledge work motivation (e.g., Kubo \& Saka, 2002; Tampoe, 1993). Secondly, studies address how motivation is linked to knowledge aspects of work, such as creativity and other facets of knowledge exploration, and cooperation and knowledge transfer in knowledge teams. Questions addressed in such studies are how motivation plays a role in the establishment of key mechanisms that will lead to knowledge becoming organizationally valuable (e.g., Amabile, 1997; Janz, Colquitt, \& Noe, 1997; Osterloh \& Frey, 2000).

In this article, we argue that understanding the effect of KM practices on motivation presumes an understanding of how motivation plays a role in knowledge work. We also argue that the second class of studies specified above deserves more attention than the first, as it aims to glance into the black box of what constitutes the knowledge elements in work. It will provide better guidance for drafting KM practices and evaluating their effectiveness than studies in the first class can. Any work is knowledge based, unless performed by an automated machine. Therefore the terms knowledge work and knowledge worker are container concepts that are low in meaning without a specification of how knowledge defines them. Themes such as creativity and knowledge transfer provide exactly those specifications. The logical sequence for addressing the connections between motivation and the placeholder of knowledge work, therefore, is first to define work motivation and specify work motivation theories, next to link them to knowledge themes, and finally to derive inspiration from that connection for KM programs aimed at furthering motivation for knowledge work. This sequence defines the structure of this article. 


\section{THE MOTIVATION FOR KNOWLEDGE-RELATED ASPECTS OF WORK}

\section{The Concept of Work Motivation and Work Motivation Theories}

Motivation concerns the question: "What is in it for me?" Motivation is about what makes people's clocks tick. That is, it concerns how behavior is instigated and inspired by the expected outcomes of that behavior defined as goals, aspects of success, performance, or in other ways. What involves restricting the motivation concept to the work situation is succinctly expressed by the title of Maccoby's (1988) monograph on work motivation: "Why Work?" Work motivation concerns the individual's degree of willingness to exert and maintain an effort towards aligning individual goals with organizational goals, organizational success, organizational performance, and so forth. Such goals, success, and performance refer to what is commonly called group motivation. The concept of work motivation is closely related to such concepts as work commitment, attachment, involvement, and engagement. These concepts refer to the degree and different aspects of emotional binding to the job. Therefore, they can serve as indicators of motivation. Work motivation is also related to job satisfaction or personal assessment of work revenues. Job satisfaction simultaneously plays the role of a cause and an effect of work motivation.

Drawing from the plethora of motivation theories that such disciplines as psychology and sociology have brought forth, organization studies have had their share in adding to the smorgasbord of motivation-related concepts, ideas, and frameworks (for an excellent overview, see Ambrose \& Kulik, 1999). Some work motivation theories appear more popular than others for addressing motivation issues with respect to knowledge work. Below we give an outline of these theories.

\section{Two-Factor Theory and Self-Determination Theory}

Probably the most used distinction in motivation discussions is that between intrinsic and extrinsic motivation. These concepts are the basic concepts of Deci and Ryan's (1985, 2004) Self-Determination Theory (SDT). They are closely related to what Herzberg $(1968,1987)$ in his TwoFactor Theory calls motivators and hygiene factors. Intrinsic motivation works through immediate need satisfaction. A person is intrinsically motivated to perform an activity when the goal of the action is thematically identical with the action itself, that is, when it is carried out for the sake of its own objectives. Extrinsic motivation works through indirect need satisfaction, for example, through monetary and symbolic compensation. Intrinsic motivation and extrinsic motivation represent positions on a continuum describing where the locus of causality or degree of self-determination lays in particular behavior. In intrinsically motivated behavior, that locus is fully internal. It moves to external and impersonal to the extent that individuals fully assimilate outside regulations or ignore these (with several intermediate positions identified; see Deci \& Ryan, 2004).

\section{Goal-Setting Theory}

Goal-Setting Theory (Locke, 1968; Locke \& Latham, 1990) states that higher performance results from specifying goals, depending on how and by whom that specification is given. Once individuals determine the goals they intend to achieve, these goals and intentions direct and motivate efforts to attain them. Studies based upon goal-setting theory indicate that levels of goal specification are related to level of success in goal attainment (see Ambrose \& Kulik, 1999). Individuals must be aware of the goal and accept it. Specific and difficult objectives lead to better achievement than vague or easy ones (Durham, Knight, \& Locke, 1997). Goals should involve a challenge; to boost motivation, they should entail an extra effort. Research has also demonstrated that participation in goal setting is critical to commitment to the goal (e.g., O'LearyKelly, Martocchio, \& Frink, 1994). Receiving feedback on goal achievement is also essential for motivation. If an employee does not get timely and accurate feedback on performance, it is impossible to know what behaviors to continue in order to achieve similar goals in the future (e.g., Carson \& Carson, 1993; Gambill, Clark, \& Wilkes, 2000).

\section{Job Characteristics Theory}

Job Characteristics Theory (JCT; Hackman \& Oldham, 1980) involves a three-stage model, specifying a set of core job characteristics that impact critical psychological states (meaningfulness, responsibility, knowledge of results). These influence a set of affective and motivational outcomes. The five job characteristics are: (1) skill variety, which describes the degree to which a job requires the exercise of a number of different skills, abilities, or talents; (2) task identity, defined as the extent to which a job requires completion of a whole and identifiable piece of work; (3) task significance, referring to the degree to which the job has an impact on the lives of other people; (4) autonomy, or the extent to which the jobholder is free to determine work procedures; and (5) feedback, or the information an individual obtains about performance effectiveness. 


\section{Self-Efficacy Theory}

Bandura's (1986, 1997) Self-Efficacy Theory links elements of expected or desired outcomes of work behavior to the perception of what feasible outcomes are, given one's capabilities and competencies. The theory is based on the premise that people are more likely to engage in certain behaviors when they believe they are capable of executing those behaviors successfully. Critical factors in the development of self-efficacy are self-regulation, setting standards and goals, self-observation, self-judgment, and self-reaction. Much empirical evidence supports Bandura's contention that self-efficacy beliefs affect how well individuals motivate themselves and persevere in the face of adversities (e.g., Gibson, 2001; Gibson, Randel, \& Earley, 2000; Pajares, 1996; Tierney \& Farmer, 2002).

\section{Main Themes of Knowledge Work Motivation}

Motivation plays a key role in knowledge work in many respects. In the literature discussing motivation issues related to knowledge aspects of work, four key themes emerge, including the overall motivation: (1) for knowledge work, (2) for knowledge creation, (3) for knowledge sharing, and (4) for the adoption of KM. The bulk of motivation studies of knowledge work address themes 2 and 3. Table 1 shows how different studies addressing these themes use the work motivation theories presented above.

\section{Overall Motivation for Knowledge Work}

Some studies link motivation to the broad class of knowledge workers. Knowledge-intensive firms show up in sta- tistics with high turnover rates, which is partly explained by the fact that individual knowledge workers identify with their profession rather than their employer, and that they need 'job hopping' to keep abreast of developments. Highly motivated employees may therefore experience a drive to change jobs on a regular basis. An intriguing object for the study of knowledge worker motivation is that high workforce turnover may also show lacking motivation (Horwitz, Heng, \& Quazi, 2003). When knowledge workers experience their work as a source of frustration, workforce turnover along with high absence rates are signs of low motivation. Tampoe (1993) shows that three key motivators for knowledge workers are personal growth, operational autonomy, and task achievement. His research shows that salary and bonuses on personal effort are not a principal motivator for knowledge workers. Research by Kubo and Saka (2002) partly contradicts this finding in that it shows the relevance of monetary incentives as a principal motivator for Japanese knowledge workers, next to such factors as personal growth and human resource development. Studies addressing motivation issues as described above treat the class of knowledge workers as a black box. As we argued in the Background section, the findings of these studies have a limited value for KM discussions because they do not specify whether the motivation mechanisms they address concern the knowledge-intensive facets of the knowledge work involved or not.

\section{Knowledge Development and Creativity}

Creativity is the first step in knowledge development and innovation. The connection between motivation and creativity has attracted much research attention for decades (e.g., Ambrose \& Kulik, 1999). Amabile (1997), a

Table 1. Motivation theories and knowledge themes: Sample studies

\begin{tabular}{lll}
\hline & $\begin{array}{l}\text { Knowledge development, } \\
\text { creativity }\end{array}$ & $\begin{array}{l}\text { Knowledge sharing, cooperation, } \\
\text { participation in communities, } \\
\text { knowledge teams }\end{array}$ \\
\hline $\begin{array}{l}\text { Self-Determination Theory (Deci } \\
\text { \& Ryan), Two-Factor Theory } \\
\text { (Herzberg) }\end{array}$ & $\begin{array}{l}\text { Amabile, 1997; Amabile et al., } \\
\text { 2004; Wilkesmann \& Rascher, } \\
\text { 2002 }\end{array}$ & $\begin{array}{l}\text { Hendriks, 1999; Huber, 2001; } \\
\text { Wilkesmann \& Rascher, 2002 }\end{array}$ \\
$\begin{array}{l}\text { Job Characteristics Theory } \\
\text { (Hackman \& Oldham) }\end{array}$ & Amabile, 1988, 1997 & $\begin{array}{l}\text { Janz, 1999; Janz et al., 1997; } \\
\text { Wilkesmann \& Rascher, 2002 }\end{array}$ \\
$\begin{array}{l}\text { Goal-Setting Theory (Locke \& } \\
\text { Latham) }\end{array}$ & $\begin{array}{l}\text { Carson \& Carson, 1993; Gambill } \\
\text { et al., 2000 }\end{array}$ & Durham et al., 1997; Reinig, 2003 \\
& $\begin{array}{l}\text { Janssen, 2000; Shalley \& Gilson, } \\
\text { 2004; Spreitzer, 1995; Tierney \& } \\
\text { Self-Efficacy Theory (Bandura) }\end{array}$ & $\begin{array}{l}\text { Cheng, 2000; McClough \& } \\
\text { Rogelberg, 2003 }\end{array}$ \\
\hline
\end{tabular}


leading researcher on what motivates creativity, is one of many researchers who stress that a particularly strong connection exists between creativity and intrinsic motivation. She summarizes this core research finding in the Intrinsic Motivation Principle: "Intrinsic motivation is conducive to creativity. Controlling extrinsic motivation is detrimental to creativity, but informational or enabling extrinsic motivation can be conducive, particularly if initial levels of intrinsic motivation are high" (Amabile, 1997, p. 46). A person's social environment can have a significant effect on that person's level of intrinsic motivation, and therefore affects that person's creativity in an indirect way. Job characteristics have been shown to play a critical role in creativity (Amabile, 1988). Research supports the idea that specific job characteristics, most notably skill variety, task identity, and autonomy, are associated with greater intrinsic motivation, especially for growth-oriented people (Smith \& Rupp, 2002). Challenging and complex jobs for which employees have the autonomy to plan their work are crucial for creativity (Shalley, Gilson, \& Blum, 2000). The effect of goal setting in creative work has been shown to be positive: research confirms that clearly stated missions, clear organizational goals, and the assignment of creativity goals are critical factors for high creativity (e.g., Carson, 2001; Carson \& Carson, 1993; Gambill et al., 2000). Elements of the work environment have also been shown to be correlated with the motivation for creativity (Amabile, 1997; Shalley \& Gilson, 2004): supervisory encouragement, workgroup supports, adequate availability of resources, absence of undue workload pressure, and other work contextual variables have been shown to have a positive impact on creativity. Most empirical studies show that working for reward can be damaging to both intrinsic motivation and creativity (see Hennessey \& Amabile, 1998). Nonetheless, rewards may support intrinsic motivation and creativity if presented carefully (Carson, 2001).

\section{Knowledge Sharing, Knowledge Teams, and Communities}

As regards knowledge transfer and knowledge sharing, which are key topics in KM debates, research stresses and shows the fundamental importance of intrinsic motivation. Knowledge sharing and associated motivation is related to a variety of subjects, such as knowledgeintensive collaboration, the formation of knowledge teams, and so forth. Several studies support the idea that intrinsic motivation for knowledge sharing is an important element in team motivation that will improve team performance (e.g., Janz, 1999; Janz et al., 1997). Osterloh and Frey (2000) argue that intrinsic motivation is particularly important for the transfer of tacit knowledge. Intrinsic motivation and extrinsic motivation are not independent. The most extensively researched phenomenon showing this is the fact that the introduction of extrinsic motivators (e.g., money) may reduce intrinsic motivation, which is discussed under the label of the 'hidden cost of reward' or the crowding-out effect (Osterloh \& Frey, 2000). Market arrangements, which only provide extrinsic motivations, are problematic when the transfer of tacit knowledge is at stake, because of this crowding-out effect. In addition, Wilkesmann and Rascher (2002) show that the importance of intrinsic motivation in knowledge transfer also derives from the fact that without it, the team element in learning will not be established, and groups cannot solve the free-rider problem. Several studies show that the context in which knowledge transfer takes place (its purpose, the support mechanisms in place, the roles played by transfer partners) lead to different motivators being important (Hendriks, 1999; Janz et al., 1997; Wasko \& Faraj, 2000). A factor such as 'challenge of work' shows to be relevant when knowledge sharing concerns the team element in learning, but not when the transfer of best practices is at stake. A sense of achievement and responsibility appear important motivators for the role of conveying to others what one has learnt. Operational autonomy appears a key motivator for acquiring knowledge from others (Hendriks, 1999; Janz et al., 1997). However, in a team setting, high task interdependence with other teams reduces the importance of autonomy as a motivator. Also, when knowledge transfer concerns communities, as a more organic form of knowledge sharing than knowledge transfer in teams, moral obligation and generalized reciprocity (that is defined as reciprocity at the level of the community rather than individuals) have been shown to define intrinsic motivation rather than motivation factors that focus on self-interest, along with the more 'selfish' motivator of keeping abreast of innovations (Wasko \& Faraj, 2000).

\section{Acceptance of KM Interventions}

Motivation is among the factors that explain whether or not KM programs and practices are successfully adopted by an organization (Bailey \& Clarke, 2001; Davenport et al., 1998; Malhotra \& Galletta, 2003; McKenzie et al., 2001). Empirical research in this domain is scarce and inconclusive. In a small-scale survey, McKenzie et al. (2001) found, perhaps not surprisingly, that an understanding and recognition of the value of a KM initiative by the end users is the best guarantee that these will be motivated to adopt the initiative. This finding suggests that a close connection between intrinsic motivation and the KM program is essential. Exploratory research by Malhotra and Galletta (2003) suggests that, next to intrinsic motivation, also 
introjected regulation (taking in a regulation for reasons of anxiety and guilt without fully accepting it; this is an extrinsic motivator) and external regulation (adopted behavior to satisfy an external demand or reward contingency; this too is an extrinsic motivator) explain for the motivation whether or not to participate in a KM initiative.

\section{Motivating Knowledge Workers}

KM as knowledge-directed intervention in organizations offers several strategies, means, and practices aimed at affecting an individual's motivation, most of which stem from organization design theories and from the HRM arena. Much research shows that work design is a key factor in the motivation of knowledge workers and that work design forms the backdrop against which additional interventions such as HRM practices gain relevance (e.g., Hackman \& Oldham, 1980; Osterloh \& Frey, 2000). Winning motivation strategies have been shown to include allowing individuals and teams the freedom to define their work, the design of challenging jobs, and ensuring the support from top management for knowledge-related initiatives (McKenzie et al., 2001). Flexibility in work practices, cash rewards for knowledge products, and recruitment practices aimed at hiring people that fit existing culture prove to be less successful motivation strategies (Despres \& Hiltrop, 1996; Horwitz et al., 2003). In line with these findings, Horwitz et al. (2003) show the strong motivational importance of what they describe as 'job crafting', or the degree of freedom for individuals to adapt the physical and cognitive elements in the task and relationship boundaries of their work. Within the broad spectrum of motivational measures for knowledge work, the class of incentive and reward systems has received special attention (e.g., Amabile, Conti, Coon, Lazenby, \& Herron, 1996; Carson, 2001; Despres \& Hiltrop, 1996; Hennessey \& Amabile, 1998; Krönig, 2001; Kubo \& Saka, 2002; McKenzie et al., 2001; Salo, 2001). Prescriptions for knowledge-friendly reward systems, which are partly backed by research, include that reward systems should be perceived as rational by the individual and the team, that they should focus on insights rather than status and hierarchical position, that they put challenge before monetary compensation, that they should involve an appropriate degree of flexibility and adaptability, and that the drafters of such systems should be aware that rewards can also demotivate because of crowding-out effects.

\section{FUTURE TRENDS}

KM researchers and practitioners show a sustained high level of interest in matters of motivation. Simultaneously, there is a growing awareness of lacking insight as to how motivation plays a role in the knowledge arena, and how and when KM may improve or decrease motivation. Therefore, a rise in research efforts in this domain may be expected. Prevailing research plans, programs, and calls for research show at least three trends in motivation research. Firstly, future research aims at establishing a conceptually more rich connection between motivation and organizational knowledge. This concerns using our growing understanding of what does and does not constitute organizational knowledge to guide inspections of motivation elements for knowledge work, instead of looking for knowledge elements in extant motivation theories. For instance, if knowledge work is not defined by knowledgeability but by ambiguity, as Alvesson (2000) argues, what does this then tell us about motivation? It also concerns an increased attention for the question how different cultures, and other situational factors, imply different motivators. In addition, an exploration of the broader landscape of motivation theories and the possible combinations between elements of existing theories in light of the discussions of organizational knowledge is necessary. Secondly, a trend can be noted toward broadening the scope of motivation research in KM. Currently, most motivation research is geared toward knowledge exploration, knowledge transfer, and their constituent themes. Also other knowledge processes, including knowledge combination, application, and retention, plus a broader set of constituent themes (e.g., aspects from learning theories) deserve attention in motivation research. Thirdly, there is a clear need of qualitative and quantitative empirical research both on the intricate relationships between motivation and knowledge aspects of work and on the effectiveness of KM programs and practices.

\section{CONCLUSION}

The motivation for knowledge work appears as an intriguing phenomenon that we are only beginning to understand. Its relevance for KM derives from the fact that it connects the content side of knowledge work with the associated aspects of knowledge work processes and knowledge-friendly organization structures to the people side of KM with its attention for talents and competences. How work is organized appears crucial for motivated knowledge workers. Their individual talents, dispositions, and intrinsic motivation are the other side of the medal that decide whether the promises of a knowledgefriendly work environment are fulfilled. Furthering our understanding of what to do and what not to do in attempts to boost knowledge work motivation requires a deepened understanding of how motivation relates to the various themes, such as creativity and knowledge sharing, that define what is commonly described as knowledge 
work. Only by lifting the veil of such container concepts as knowledge work and knowledge worker may we hope to unravel the motivation aspects involved.

\section{REFERENCES}

Alvesson, M. (2000). Social identity and the problem of loyalty in knowledge-intensive companies. Journal of Management Studies, 37(8), 1101-1123.

Amabile, T.M. (1988). A model of creativity and innovation in organizations. In B.M. Staw \& L.L. Cummings (Eds.), Research in organizational behavior (Vol. 10, pp. 123-167). Greenwich, CT: JAI Press.

Amabile, T.M. (1997). Motivating creativity in organizations: On doing what you love and loving what you do. California Management Review, 40(1), 39-58.

Amabile, T.M., Conti, R., Coon, H., Lazenby, J., \& Herron, M. (1996). Assessing the work environment for creativity. Academy of Management Journal, 39(5), 1154-1184.

Amabile, T.M., Schatzel, E.A., Moneta, G.B., \& Kramer, S.J. (2004). Leader behaviors and the work environment for creativity: Perceived leader support. Leadership Quarterly, 15(1), 5-32.

Ambrose, M.L., \& Kulik, C.T. (1999). Old friends, new faces: Motivation research in the 1990s. Journal of Management, 25(3), 231-292.

Bailey, C., \& Clarke, M. (2001). Managing knowledge for personal and organizational benefit. Journal of Knowledge Management, 5(1), 58-68.

Bandura, A. (1986). Social foundations of thought and action: A social cognitive theory. Englewood Cliffs, NJ: Prentice-Hall.

Bandura, A. (1997). Self-efficacy: The exercise of control. New York: Freeman.

Carson, P.P. (2001). Rewarding excellence: Pay strategies for the new economy. Organizational Dynamics, 29(3), 228-229.

Carson, P.P., \& Carson, K.D. (1993). Managing creativity enhancement through goal-setting and feedback. Journal of Creative Behavior, 27(1), 36-45.

Cheng, E.W.L. (2000). Test of the MBA knowledge and skills transfer. International Journal of Human Resource Management, 11(4), 837-852.

Davenport, T., DeLong, D., \& Beers, M. (1998). Successful knowledge management projects. Sloan Management Review, 39(2), 43-57.
Deci, E.L., \& Ryan, R.M. (1985). Intrinsic motivation and self-determination in human behavior. London: Plenum.

Deci, E.L., \& Ryan, R.M. (2004). Handbook of self-determination research. Rochester, NY: University of Rochester Press.

Despres, C., \& Hiltrop, J.-M. (1996). Compensation for technical professionals in the knowledge age. Research Technology Management, 39(5), 48-55.

Durham, C.C., Knight, D., \& Locke, E.A. (1997). Effects of leader role, team-set goal difficulty, efficacy, and tactics on team effectiveness. Organizational Behavior and Human Decision Processes, 72(2), 203-231.

Gambill, S.E., Clark, W.J., \& Wilkes, R.B. (2000). Toward a holistic model of task design for IS professionals. Information \& Management, 37(5), 217-228.

Gibson, C.B. (2001). Me and us: Differential relationships among goal-setting training, efficacy and effectiveness at the individual and team level. Journal of Organizational Behavior, 22(7), 789-808.

Gibson, C.B., Randel, A.E., \& Earley, P.C. (2000). Understanding group efficacy - an empirical test of multiple assessment methods. Group \& Organization Management, 25(1), 67-97.

Hackman, J.R., \& Oldham, G.R. (1980). Work redesign. Reading, MA: Addison-Wesley.

Hendriks, P.H.J. (1999). Why share knowledge? The influence of ICT on the motivation for knowledge sharing. Knowledge and Process Management, 6(2), 91-100.

Hennessey, B.A., \& Amabile, T.M. (1998). Reward, intrinsic motivation, and creativity. American Psychologist, 53(6), 674-675.

Herzberg, F. (1968). Work and the nature of man. London: Granada Publishing.

Herzberg, F. (1987). One more time-how do you motivate employees? Harvard Business Review, 65(5), 109-120.

Horwitz, F.M., Heng, C.T., \& Quazi, H.A. (2003). Finders, keepers? Attracting, motivating and retaining knowledge workers. Human Resource Management Journal, 13(4), 23-44.

Huber, G.P. (2001). Transfer of knowledge in knowledge management systems: Unexplored issues and suggested studies. European Journal of Information Systems, 10(2), 72-79.

Janssen, O. (2000). Job demands, perceptions of effortreward fairness and innovative work behavior. Journal of 
Occupational and Organizational Psychology, 73(3), 287-302.

Janz, B.D. (1999). Self-directed teams in IS: Correlates for improved systems development work outcomes. Information \& Management, 35(3), 171-192.

Janz, B.D., Colquitt, J.A., \& Noe, R.A. (1997). Knowledge worker team effectiveness: The role of autonomy, interdependence, team development, and contextual support variables. Personnel Psychology, 50(4), 877-904.

Krönig, J. (2001). Do incentive systems for knowledge management work? An empirical study on the design and influence of incentive systems of knowledge creation and transfer in manufacturing-based industry. Bern: Lang.

Kubo, I., \& Saka, A. (2002). An inquiry into the motivations of knowledge workers in the Japanese financial industry. Journal of Knowledge Management, 6(3), 262271.

Locke, E.A. (1968). Toward a theory of task motivation and incentives. Organizational Behavior and Human Performance, 3, 157-189.

Locke, E.A., \& Latham. (1990). A theory of goal setting and task performance. Englewood Cliffs, NJ: PrenticeHall.

Maccoby, M. (1988). Why work: Leading the new generation. New York: Simon \& Schuster.

Malhotra, Y., \& Galletta, D. (2003, January). Role of commitment and motivation in knowledge management systems implementation: Theory, conceptualization, and measurement of antecedents of success. Proceedings of the Hawaii International Conference on Systems Science, Hawaii.

McClough, A.C., \& Rogelberg, S.G. (2003). Selection in teams: An exploration of the teamwork knowledge, skills, and ability test. International Journal of Selection and Assessment, 11(1), 56-66.

McKenzie, J., Truc, A., \& Winkelen, C.V. (2001). Winning commitment for knowledge management initiatives. Journal of Change Management, 2(2), 115-127.

O’Leary-Kelly, A.M., Martocchio, J.J., \& Frink, D.D. (1994). A review of the influence of group goals on groupperformance. Academy of Management Journal, 37(5), 1285-1301.

Osterloh, M., \& Frey, B.S. (2000). Motivation, knowledge transfer, and organizational forms. Organization Science, 11(5), 538-550.
Pajares, F. (1996). Self-efficacy beliefs in academic settings. Review of Educational Research, 66(4), 543-578.

Reinig, B.A. (2003). Toward an understanding of satisfaction with the process and outcomes of teamwork. Journal of Management Information Systems, 19(4), 65-83.

Salo, A.A. (2001). Incentives in technology foresight. International Journal of Technology Management, 21 (78), 694-710.

Shalley, C.E., \& Gilson, L.L. (2004). What leaders need to know: A review of social and contextual factors that can foster or hinder creativity. Leadership Quarterly, 15(1), 33-53.

Shalley, C.E., Gilson, L.L., \& Blum, T.C. (2000). Matching creativity requirements and the work environment: Effects on satisfaction and intentions to leave. Academy of Management Journal, 43(2), 215-223.

Smith, A.D., \& Rupp, W.T. (2002). Communication and loyalty among knowledge workers: A resource of the firm theory view. Journal of Knowledge Management, 6(3), 250-261.

Spreitzer, G.M. (1995). Psychological empowerment in the workplace-dimensions, measurement, and validation. Academy of Management Journal, 38(5), 1442-1465.

Tampoe, M. (1993). Motivating knowledge workers- the challenge for the 1990s. Long Range Planning, 26(3), 4955 .

Tierney, P., \& Farmer, S.M. (2002). Creative self-efficacy: Its potential antecedents and relationship to creative performance. Academy of Management Journal, 45(6), 1137-1148.

Tierney, P., \& Farmer, S.M. (2004). The Pygmalion process and employee creativity. Journal of Management, 30(3), 413-432.

Wasko, M.M., \& Faraj, S. (2000). "It is what one does": Why people participate and help others in electronic communities of practice. Journal of Strategic Information Systems, 9(2-3), 155-173.

Wilkesmann, U., \& Rascher, I. (2002). Motivational and structural prerequisites of knowledge management (No. 02-2). Bochum: Fakultät für Sozialwissenschaft, RuhrUniversität Bochum.

\section{KEY TERMS}

Extrinsic Motivation: The motivation to engage in an activity as a means to an end, based on the belief that 
participation will result in desirable outcomes such as a reward or avoidance of punishment.

Goal-Setting Theory: This theory, developed by Locke and Latham, states that individuals make calculated decisions about their desired goals, and that these goals and intentions, once established, direct and motivate efforts to attain them.

Intrinsic Motivation: The motivation to engage in an activity for its own sake, because the activity is considered enjoyable, worthwhile, or important.

Job Characteristics Theory: This motivation theory, which stems from Hackman and Oldham, identifies several characteristics of jobs, such as skill variety and autonomy, that influence the experienced meaningfulness of work, and therefore the internal motivation and job satisfaction of workers.
Motivation: An energizing force directed toward a specific target considered to explain behavior.

Self-Determination Theory: A motivation theory, developed by Deci and Ryan, which suggests that individuals have three innate psychological needs: autonomy, competence, and relatedness. It distinguishes between intrinsically motivated, or autonomous, self-determined activity, and extrinsically motivated activity, which is more controlled (i.e., less autonomous).

Self-Efficacy Theory: This motivation theory, developed by Bandura, posits that motivation is the combined product of beliefs about whether one is capable of performing (or learning) some task, and beliefs about whether such performance will lead to desirable outcomes.

Work Motivation: Involves the restriction to those motivation elements that relate to the work situation; concerns the individual's degree of willingness to work towards organizational targets. 